\title{
Risk factors for stunting among under-fives in Libya
}

\author{
Adel El Taguri ${ }^{1,2, *}$, Ibrahim Betilmal ${ }^{3}$, Salah Murad Mahmud ${ }^{4}$, Abdel Monem Ahmed ${ }^{5}$, \\ Olivier Goulet ${ }^{1}$, Pilar Galan ${ }^{6}$ and Serge Hercberg ${ }^{6}$ \\ ${ }^{1}$ Hôpital Necker Enfants Malades, 149 rue de Sèvres, F-75743 Paris Cedex 15, France: ${ }^{2}$ Department of Family \\ and Community Medicine, Alfateh University, PO Box 13229, Tripoli, Libya: ${ }^{3}$ Eastern Mediterranean Regional \\ Office, World Health Organization, Cairo, Egypt: ${ }^{4}$ Department of Community Health Sciences, University of \\ Manitoba, Winnipeg, Manitoba, Canada: ${ }^{5}$ Arab Council for Childhood \& Development, Pan Arab Project for \\ Family Health, League of Arab States: ${ }^{6}$ Center de Recherche en Nutrition Humain (CRNH), UMR U557 \\ INSERM/UI 125 INRA/CNAM, Paris, France
}

Submitted 26 July 2007: Accepted 18 August 2008: First published online 15 September 2008

\begin{abstract}
Objective: Stunting is a chronic condition reflecting poor nutrition and health. Our aim was to ascertain major predictors of stunting in children $<5$ years old in Libya. Population and methods: A nationally representative, cross-sectional, two-stage stratified cluster sample survey enrolled 4549 under-fives from 6707 households. Logistic regression was used to determine individual risk factors in bivariate and multivariate analyses.

Results: Anthropometric measurements were available for 4498 children. Among the 929 stunted children (20.7\%), 495 were boys (53.3\%) and 434 were girls $(46 \cdot 5 \%)$. In multivariate analysis, risk factors were young age $(1-2$ years: $\mathrm{OR}=$ $2 \cdot 32,95 \%$ CI $1 \cdot 67,3 \cdot 22 ; 2-3$ years: OR $=1 \cdot 64,95 \%$ CI $1 \cdot 22,2 \cdot 21)$, resident of Al-Akhdar (OR $=1 \cdot 67,95 \%$ CI $1 \cdot 08,2 \cdot 58)$, being a boy $(\mathrm{OR}=1 \cdot 28,95 \%$ CI $1 \cdot 05$, $1 \cdot 55$ ), having a less educated father (illiterate: OR $=2 \cdot 10,95 \%$ CI $1 \cdot 17,3 \cdot 77$; preparatory school: $\mathrm{OR}=1 \cdot 71,95 \% \mathrm{CI} 1 \cdot 11,2 \cdot 65)$, poor psychosocial stimulation (no family visits or trips: $\mathrm{OR}=1 \cdot 52,95 \% \mathrm{CI} 1 \cdot 07,2 \cdot 16$; father rarely/never plays with child: $\mathrm{OR}=2 \cdot 24,95 \% \mathrm{CI} 1 \cdot 20,4 \cdot 16)$, filtered water $(\mathrm{OR}=8 \cdot 45,95 \% \mathrm{CI}$ $2 \cdot 31,30 \cdot 95)$, throwing garbage in the street $(\mathrm{OR}=13 \cdot 81,95 \% \mathrm{CI} 2 \cdot 33,81 \cdot 72)$, diarrhoea $(\mathrm{OR}=1 \cdot 58,95 \% \mathrm{CI} 1 \cdot 09,2 \cdot 29)$ and low birth weight $(\mathrm{OR}=1 \cdot 8,95 \% \mathrm{CI}$ $1 \cdot 17,2 \cdot 40)$. Protective factors were older age of father $(\mathrm{OR}=0 \cdot 53,95 \% \mathrm{CI} 0 \cdot 32$, $0 \cdot 90)$ and water storage $(\mathrm{OR}=0 \cdot 70,95 \% \mathrm{CI} 0 \cdot 54,0 \cdot 90)$. These variables only explained $20 \%$ of cases of stunting.

Conclusion: Various multilevel actions are needed to improve nutritional status of under-fives in Libya. At risk-groups include those with young age (1-3 years), resident of Al-Akhdar region, boys, father's low educational level, poor psychosocial stimulation, poor housing environment, diarrhoea and low birth weight.
\end{abstract}

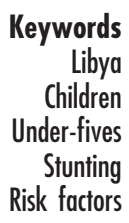

Nutritional status is a sensitive indicator of the quality of life in a given population ${ }^{(1,2)}$. Despite global improvement in the health of children aged $<5$ years in developing countries, undernutrition remains an important public health problem $^{(3,4)}$. More than half of deaths of children in these countries are related to undernutrition ${ }^{(5)}$. Undernutrition profoundly affects human function, with both individual and transgenerational effects. Individual effects include the well-known undernutrition-infection vicious cycle, while transgenerational effects refer to a similar vicious spiral that extends to forthcoming offspring and induces permanent effects on mental, social and physical well-being. These effects occur even in mild-to-moderate cases ${ }^{(3)}$. Undernutrition also affects society at large because it leads to reduced productivity and limited ability to escape the consequences of poverty ${ }^{(3,6,7)}$.
Reduction of the prevalence of undernutrition in under-fives is a top priority to reduce child mortality and morbidity. Reduction of undernutrition prevalence by $50 \%$ between 1990 and 2015 is among the most important targets of the first Millennium Development Goal. Nevertheless, progress remains slow, and most international goals set for improving child nutrition and health were not met by 2000 .

Stunting (i.e. low height-for-age) is a chronic condition that reflects poor linear growth accumulated during preand/or postnatal periods because of poor nutrition and/or health. It is more difficult to treat than acute forms of undernutrition such as wasting. Its relationship to micronutrient deficiencies, obesity (particularly the abdominal type) and chronic diseases makes it an important health hazard even for countries in transition. Causes of stunting 
are multifactorial with roots in many sectors of development such as education, demography, agriculture and rural development ${ }^{(8,9)}$. Identification of the causes in a particular setting implies the investigation of complex interactions between these multiple interrelated social, economic and environmental determinants. Such determinants usually occupy different positions in the dependence chain and they cannot adequately be modelled by including them all in a linear regression analysis ${ }^{(10,11)}$. They can be better understood within an integrated conceptual framework that considers these factors and their interactions ${ }^{(8,11,12)}$. One example of such a model is the UNICEF conceptual framework. This framework, which was developed in 1990 as a part of UNICEF's nutritional strategy ${ }^{(8)}$, provides a holistic and pragmatic approach. It classifies the causes of undernutrition into three categories that account for the complexity of the nutritional status of children: (i) basic causes at the societal level; (ii) underlying causes at the household/family level; and (iii) immediate causes. Factors at one level influence other levels.

Libya is classified as a low-prevalence area of wasting $(3 \cdot 3 \%)$ and stunting $(15 \cdot 1 \%)$ using the National Center for Health Statistics/Centers for Disease Control and Prevention/WHO reference growth curves ${ }^{(13,14)}$. Stunting in Libya is more prevalent in certain geographic regions, in rural areas and in underprivileged groups ${ }^{(13,15)}$. Rates are as high as $28 \%$ in Al-Akhdar region when the newly published growth charts from the WHO Multiple Centre Growth Reference Study ${ }^{(16)}$ are used. As such, the country would be reclassified as an intermediate-level country ${ }^{(15)}$.

Improvement in nutritional status needs effective planning that accounts for the underlying risk factors, identifying at-risk subgroups and permitting targeted interventions. There is a paucity of studies that would permit a fuller contextual assessment of the patterns and determinants of undernutrition in Libya. Analysis of national cross-sectional surveys can provide clues to fill this gap. The Libyan Maternal and Child Health Survey (LMCHS), undertaken as part of the Pan Arab Project for Child Development (PAPCHILD), is the first nationally representative maternal and child health survey ever undertaken in Libya ${ }^{(13,17)}$. The present study is a secondary analysis of the raw data from the LMCHS. The aim was to ascertain predictors of childhood stunting in children aged $<5$ years in this population.

\section{Population and methods}

\section{Design}

The design, methods and nutritional status of under-fives in Libya from the LMCHS are described in more detail elsewhere ${ }^{(13,15,17)}$. The LMCHS is a cross-sectional, nationally representative, two-stage stratified probability cluster sample of 6707 households that was undertaken during the summer of 1995 . The country was divided into seven administrative regions. These regions were three costal (Benghazi, Tripoli and Al-Zaouia), two mountainous (Al-Akhdar and Al-Gharbi) and two predominantly desert areas (Sirt and Sabha). Each region was divided into urban and rural zones. In the first stage, a total of 307 sampling units, including 102 units from rural areas, were selected randomly. In the second stage, each sampling unit was divided into five segments of equal sizes. All households in one randomly selected segment were included in the sample. All children younger than 60 months at the time of the survey were eligible for recruitment.

\section{Data and outcome measures}

Data were collected in interviews with mothers during household visits using the three different standard PAPCHILD questionnaires with a few modifications to conform to local patterns of disease and determinants ${ }^{(17)}$. The child questionnaire contained items related to child health and its determinants such as vaccination, birth, nutrition, etc. The reproductive health questionnaire contained items on the mother's health and reproductive history. The third questionnaire gathered data on household characteristics and the surrounding environment such as the availability of safe water supply, sanitation facilities and garbage collection. Weight, length/height and age data were used to calculate $Z$ scores of height-for-age in comparison with the newly published WHO growth curve. Stunting was defined as a length/height more than two standard deviations below the median height/length-for-age of the WHO Child Growth Standards from the WHO Multicentre Growth Reference Study ${ }^{(16)}$. The independent variables that were chosen for their possible association with stunting are shown in Table 1 . These variables were organized according to the conceptual framework developed by $\mathrm{UNICEF}^{(8)}$. Socio-economic classification was based on the combination of an asset index of households with its area characteristics, and a locally validated socio-economic classification that incorporates parental occupation and education $^{(18)}$.

\section{Statistical analysis}

Data were analysed using WHO Anthro 2005 software (WHO, Geneva, Switzerland) and SPSS version 13 (SPSS Inc., Chicago, IL, USA) statistical software package. The WHO Anthro 2005 program considers $Z$-score values for length/height-for-age $<-6$ as outliers. Each independent variable was individually evaluated in bivariate analyses for possible correlation with stunting. Statistical analysis with logistic regression was performed by SPSS, determining for each of the variables the odds ratio, 95\% confidence interval and statistical significance of the association with stunting. Only statistically significant risk factors are presented here. The level of significance was set at $P<0 \cdot 05$. In the final stage, in addition to the variables that were identified as significant in the bivariate analyses, some other potentially confounding variables as 
Table 1 Variables assessed for their possible association with stunting

Basic determinants

Region of residence; urbanization; gender; age; socio-economic conditions

II Underlying determinants

Family and caregiver conditions

Main caregiver; mother's age and age at birth; living arrangements; change of residence; type of previous residence; educational state of mother; listening, watching and reading of media; currently working for cash; working for cash before or after marriage; single mother; extended family; multiple wives; poor family social life

Reproductive history of mother

Age at menarche; age at first marriage; birth order of the child; number of children; blood relation with husband; history of prematurity, stillbirth, abortion and previous sibling deaths

Father's attributes

Educational state; residence in the last 3 months; playing with the child; earning regular wages

Health services

Immunizations; check-ups during pregnancy; birth order; type, place and complications of delivery; use of Caesarean section

Household environment

Area of residence and household characteristics: dwelling type and ownership; number of rooms and bedrooms; keeping animals; kitchen location and fuel used; source, storage and treatment of drinking water; type and location of toilet facilities; collection, location and disposal of garbage; state of the area around dwelling (flooded or stagnant water)

III Immediate determinants

Diet

Feeding history of the child*: onset, duration and practices of breast-feeding, infant formula-feeding and bottle-feeding age of introduction of powdered, animal and pasteurized bottle milk; introduction of solid foods; type of weaning; giving rice, juice, herbal drinks, preserved baby foods or family foods

Health

Diarrhoea; cough; fever; otitis; conjunctivitis; accidents or other illnesses; measles infection; weight at birth

${ }^{*}$ Optimal breast-feeding was considered if breast-feeding started early, if weaning started at 6-8 months of age and if breast-feeding continued for $>12$ months; whereas if weaning started between 4 and 6 months of age, breast-feeding was considered appropriate.

indicated by $P<0.5$ were also selected. These were all put together in a single logistic regression model to determine their net effects on stunting.

\section{Results}

Anthropometric measurements were available for 4498 children. Among the 929 stunted children (20.7\%), there were 495 boys $(22 \cdot 2 \%)$ and 434 girls (19.4\%). Other basic attributes of the children participating in the survey are shown in Table 2.

In bivariate analysis, various significant factors increasing (Table 3) or decreasing (Table 4) the risk of stunting were found. Basic determinants included age 1-3 years, with the second year having the highest risk even in comparison with the first year $(\mathrm{OR}=1 \cdot 31,95 \% \mathrm{CI} 1 \cdot 04$, $1 \cdot 64, P<0 \cdot 02$ ), being a boy, belonging to less privileged
Table 2 Basic attributes of under-fives involved in the Libyan Maternal and Child Health Survey, 1995

\begin{tabular}{|c|c|c|}
\hline Variable & $n$ & $\%$ \\
\hline \multicolumn{3}{|l|}{ Age of child (years) } \\
\hline$<1$ & 780 & $17 \cdot 3$ \\
\hline $1-<2$ & 895 & $19 \cdot 9$ \\
\hline $2-<3$ & 968 & $21 \cdot 5$ \\
\hline $3-<4$ & 983 & 21.9 \\
\hline $4-<5$ & 871 & $19 \cdot 4$ \\
\hline \multicolumn{3}{|l|}{ Gender } \\
\hline Boys & 2231 & $49 \cdot 6$ \\
\hline Girls & 2267 & $50 \cdot 4$ \\
\hline \multicolumn{3}{|c|}{ Socio-economic class } \\
\hline Privileged & 870 & $19 \cdot 3$ \\
\hline Intermediate & 2877 & $64 \cdot 0$ \\
\hline Underprivileged & 750 & $16 \cdot 7$ \\
\hline \multicolumn{3}{|l|}{ Area } \\
\hline Urban & 3135 & $69 \cdot 7$ \\
\hline Rural & 1363 & $30 \cdot 3$ \\
\hline \multicolumn{3}{|l|}{ Region } \\
\hline Al-Akhdar & 553 & $12 \cdot 3$ \\
\hline Benghazi & 604 & $13 \cdot 4$ \\
\hline Sirt & 631 & $14 \cdot 0$ \\
\hline Tripoli & 1513 & $33 \cdot 6$ \\
\hline Al-Zaouia & 407 & $9 \cdot 1$ \\
\hline Al-Gharbi & 487 & $10 \cdot 8$ \\
\hline Sabha & 303 & $6 \cdot 7$ \\
\hline \multicolumn{3}{|l|}{ Degree of stunting } \\
\hline Mild & 1167 & $25 \cdot 9$ \\
\hline Moderate & 591 & $13 \cdot 1$ \\
\hline Severe & 324 & $7 \cdot 2$ \\
\hline
\end{tabular}

groups, living in rural areas and being a resident of Al-Akhdar, Sirt, Al-Zaouia or Al-Gharbi regions. Underlying determinants found included family and caregiver conditions such as consanguinity, large family size (having $\geq 4$ siblings in the family), low paternal and/or maternal education and limited psychosocial stimulation (absent or rare interaction between the child and father, absence of external social contact, absence of media contact). Meanwhile, being a first or a single child decreased the risk for stunting. Other underlying determinants included poor utilization of health services (absence or poor follow-up during pregnancy, incomplete immunization). Delivery in a private health establishment decreased the risk. Housing environment such as type of dwelling, lack of safe water supply, inadequate sanitation and garbage collection were among the underlying determinants that increased the risk of stunting. Many immediate factors related to feeding practices and health status such as low birth weight and diarrhoea were found also to increase the risk of stunting. Onset of weaning at 4-6 months of age rather than 6-8 months and a large birth weight decreased the risk for stunting.

The logistic regression model for multivariate analysis included the factors reported above in addition to some other potentially confounding variables such as father's age, father's education and using water from wells without pumps. Overall, the model was significantly associated with stunting, but it explained only $20 \%$ of the variance as indicated by its $R^{2}$ value (Table 5 ). 
Table 3 Bivariate analysis of factors associated with increased risk for stunting in under-fives in Libya: secondary analysis of data from the Libyan Maternal and Child Health Survey, 1995

\begin{tabular}{|c|c|c|c|c|c|}
\hline \multicolumn{2}{|c|}{ Risk factor } & \multirow[t]{2}{*}{$n / N$} & \multirow[t]{2}{*}{ OR } & \multirow[t]{2}{*}{$95 \% \mathrm{Cl}$} & \multirow[t]{2}{*}{$P$} \\
\hline I & Basic determinants & & & & \\
\hline & Living in a rural area & $316 / 1363$ & $1 \cdot 24$ & $1 \cdot 07,1 \cdot 45$ & 0.006 \\
\hline & Age (ref: $4-<5$ years) & $138 / 871$ & $1 \cdot 00$ & - & \\
\hline & $<1$ year & $172 / 780$ & 1.50 & $1 \cdot 17,1.92$ & 0.001 \\
\hline & $1-<2$ years & 242/896 & 1.96 & $1 \cdot 55,2 \cdot 47$ & 0.000 \\
\hline & $2-<3$ years & $204 / 968$ & $1 \cdot 42$ & $1 \cdot 12,1 \cdot 80$ & 0.004 \\
\hline & Region (ref: Benghazi) & $89 / 604$ & $1 \cdot 00$ & - & \\
\hline & Al-Akhdar & $154 / 552$ & $2 \cdot 24$ & $1 \cdot 67,3 \cdot 00$ & $0 \cdot 000$ \\
\hline & Sirt & $157 / 631$ & 1.92 & $1 \cdot 44,2 \cdot 56$ & 0.000 \\
\hline & Al-Zaouia & $86 / 407$ & $1 \cdot 55$ & $1 \cdot 12,2 \cdot 15$ & 0.01 \\
\hline & Al-Gharbi & $122 / 488$ & 1.92 & $1 \cdot 42,2 \cdot 61$ & 0.000 \\
\hline & Boys & $495 / 2230$ & $1 \cdot 21$ & $1 \cdot 05,1 \cdot 40$ & 0.01 \\
\hline & Socio-economic class (ref: Privileged) & $150 / 870$ & $1 \cdot 00$ & - & \\
\hline & Intermediate & $591 / 2877$ & $1 \cdot 24$ & $1 \cdot 02,1 \cdot 51$ & 0.03 \\
\hline & Underprivileged & $188 / 750$ & $1 \cdot 61$ & $1 \cdot 27,2 \cdot 05$ & $0 \cdot 000$ \\
\hline \multirow[t]{53}{*}{ II } & \multicolumn{5}{|l|}{ Underlying determinants } \\
\hline & \multicolumn{5}{|l|}{ Family and caregiver conditions } \\
\hline & Consanguinity (ref: No relation) & $452 / 2381$ & 1.00 & - & \\
\hline & Husband is a paternal cousin & $328 / 1461$ & $1 \cdot 24$ & $1 \cdot 05,1 \cdot 45$ & 0.01 \\
\hline & Husband is a maternal cousin & $122 / 523$ & $1 \cdot 30$ & $1 \cdot 03,1.63$ & 0.03 \\
\hline & Family goes on no trips or visits & $144 / 482$ & $1 \cdot 77$ & $1 \cdot 42,2 \cdot 20$ & 0.000 \\
\hline & Educational status of mother (ref: University) & $39 / 301$ & $1 \cdot 00$ & - & \\
\hline & Illiterate & $345 / 1507$ & $2 \cdot 02$ & $1 \cdot 41,2 \cdot 89$ & 0.000 \\
\hline & Read and/or write & $106 / 504$ & $1 \cdot 81$ & $1 \cdot 22,2 \cdot 70$ & 0.004 \\
\hline & Primary & $184 / 839$ & 1.91 & $1 \cdot 31,2 \cdot 78$ & 0.001 \\
\hline & Preparatory & $128 / 666$ & $1 \cdot 62$ & $1 \cdot 10,2 \cdot 39$ & 0.02 \\
\hline & Secondary & $112 / 614$ & 1.51 & $1 \cdot 02,2 \cdot 24$ & $0 \cdot 04$ \\
\hline & Family does not watch television & $94 / 323$ & $1 \cdot 75$ & $1 \cdot 35,2 \cdot 26$ & 0.000 \\
\hline & Family does not listen to radio & $461 / 2100$ & $1 \cdot 17$ & $1 \cdot 01,1 \cdot 35$ & 0.04 \\
\hline & Number of siblings (ref: $2-4$ ) & $302 / 1494$ & 1.00 & - & \\
\hline & $>5$ & $391 / 1743$ & $1 \cdot 18$ & $1 \cdot 00,1 \cdot 40$ & 0.05 \\
\hline & Father plays with child (ref: Almost every day) & $585 / 3011$ & $1 \cdot 00$ & - & \\
\hline & Rarely/never & $31 / 90$ & $2 \cdot 20$ & $1 \cdot 41,3 \cdot 42$ & 0.001 \\
\hline & Sometimes & 291/1277 & $1 \cdot 22$ & $1 \cdot 04,1 \cdot 43$ & 0.013 \\
\hline & Educational status of father (ref: University) & 79/550 & 1.00 & & \\
\hline & Illiterate & $122 / 487$ & $2 \cdot 00$ & $1 \cdot 46,2 \cdot 73$ & 0.000 \\
\hline & Read and/or write & $89 / 455$ & 1.47 & $1 \cdot 05,2 \cdot 04$ & 0.02 \\
\hline & Primary & $174 / 921$ & $1 \cdot 39$ & $1 \cdot 04,1 \cdot 86$ & 0.03 \\
\hline & Preparatory & $207 / 910$ & $1 \cdot 76$ & $1 \cdot 33,2 \cdot 34$ & 0.000 \\
\hline & Secondary & $210 / 944$ & $1 \cdot 72$ & $1 \cdot 29,2 \cdot 28$ & 0.000 \\
\hline & \multicolumn{5}{|l|}{ Health services } \\
\hline & Mother had no check-ups during pregnancy & 209/868 & $1 \cdot 29$ & $1 \cdot 08,1.53$ & 0.005 \\
\hline & Place of delivery (ref: Public health establishment) & $815 / 4022$ & $1 \cdot 00$ & - & \\
\hline & Home & $79 / 267$ & $1 \cdot 65$ & $1 \cdot 26,2 \cdot 17$ & $0 \cdot 000$ \\
\hline & Others & $4 / 6$ & $7 \cdot 87$ & $1 \cdot 43,43 \cdot 45$ & 0.02 \\
\hline & Incomplete immunization & $175 / 717$ & $1 \cdot 28$ & $1 \cdot 06,1 \cdot 55$ & 0.009 \\
\hline & \multicolumn{5}{|l|}{ Household environment } \\
\hline & Dwelling type (ref: Apartment) & $88 / 578$ & $1 \cdot 00$ & - & \\
\hline & Popular & $252 / 1216$ & $1 \cdot 45$ & $1 \cdot 11,1 \cdot 89$ & 0.006 \\
\hline & Traditional & 198/797 & $1 \cdot 82$ & $1 \cdot 38,2 \cdot 41$ & 0.000 \\
\hline & Modern & $342 / 1789$ & $1 \cdot 31$ & $1 \cdot 01,1 \cdot 69$ & 0.04 \\
\hline & Hut and house made from fur & 22/91 & $1 \cdot 79$ & $1 \cdot 06,3 \cdot 04$ & 0.03 \\
\hline & Others & $27 / 28$ & $149 \cdot 48$ & $19 \cdot 83,1126 \cdot 81$ & 0.000 \\
\hline & Kitchen location (ref: Inside dwelling) & $873 / 4296$ & $1 \cdot 00$ & - & \\
\hline & Outside dwelling & $49 / 185$ & $1 \cdot 41$ & $1 \cdot 01,1 \cdot 97$ & $0 \cdot 04$ \\
\hline & No kitchen & $7 / 17$ & $2 \cdot 80$ & $1 \cdot 09,7 \cdot 21$ & 0.03 \\
\hline & Source of drinking water (ref: Pipe system) & $521 / 2522$ & 1.00 & - & \\
\hline & Wells without pump & $88 / 318$ & $1 \cdot 46$ & $1 \cdot 12,1 \cdot 90$ & 0.005 \\
\hline & Rainwater catchment & $23 / 70$ & $1 \cdot 84$ & $1 \cdot 11,3 \cdot 06$ & 0.02 \\
\hline & Water storage (ref: No water storage) & $231 / 1068$ & $1 \cdot 00$ & - & \\
\hline & Tin container & $25 / 76$ & $1 \cdot 80$ & $1 \cdot 09,2 \cdot 96$ & 0.02 \\
\hline & Other & 49/155 & $1 \cdot 69$ & $1 \cdot 17,2 \cdot 44$ & 0.005 \\
\hline & Water treatment (ref: No treatment) & $885 / 4305$ & $1 \cdot 00$ & - & \\
\hline & Treatment by filtering & $7 / 11$ & $6 \cdot 01$ & $1 \cdot 82,19 \cdot 82$ & 0.003 \\
\hline & Type of toilet facilities (ref: Flush toilet with sewer) & 438/2372 & 1.00 & - & \\
\hline & Latrine with container & $165 / 612$ & $1 \cdot 63$ & $1 \cdot 32,2 \cdot 00$ & 0.000 \\
\hline & Pit & $17 / 35$ & $4 \cdot 06$ & $2 \cdot 08,7 \cdot 93$ & 0.000 \\
\hline & Open air & $17 / 53$ & 2.09 & $1 \cdot 16,3 \cdot 76$ & 0.02 \\
\hline
\end{tabular}


Table 3 Continued

\begin{tabular}{|c|c|c|c|c|}
\hline Risk factor & $n / N$ & OR & $95 \% \mathrm{Cl}$ & $P$ \\
\hline Garbage disposal method (ref: Plastic bags) & $288 / 1609$ & 1.00 & - & \\
\hline Container without lid & $434 / 1871$ & $1 \cdot 38$ & $1 \cdot 17,1 \cdot 63$ & 0.000 \\
\hline Thrown in street & $14 / 44$ & $2 \cdot 18$ & $1 \cdot 15,4 \cdot 14$ & 0.02 \\
\hline Others & 9/15 & $7 \cdot 26$ & $2 \cdot 58,20 \cdot 44$ & $0 \cdot 000$ \\
\hline Garbage container located outside dwelling & $276 / 1182$ & $1 \cdot 38$ & $1 \cdot 13,1 \cdot 70$ & 0.002 \\
\hline \multicolumn{5}{|l|}{ III Immediate determinants } \\
\hline Sudden weaning & $399 / 1899$ & $1 \cdot 29$ & $1 \cdot 08,1 \cdot 54$ & 0.004 \\
\hline Health conditions of the child & & & & \\
\hline Diarrhoea & $94 / 339$ & 1.53 & $1 \cdot 19,1 \cdot 96$ & 0.001 \\
\hline Weight at birth (ref: Normal) & $758 / 3750$ & $1 \cdot 00$ & - & \\
\hline Low birth weight & $88 / 289$ & $1 \cdot 74$ & $1 \cdot 34,2 \cdot 26$ & 0.000 \\
\hline
\end{tabular}

$n$, number of stunted children in the category; $N$, total number of children in the category.

Table 4 Bivariate analysis of factors associated with decreased risk for stunting in under-fives in Libya: secondary analysis of data from the Libyan Maternal and Child Health Survey, 1995

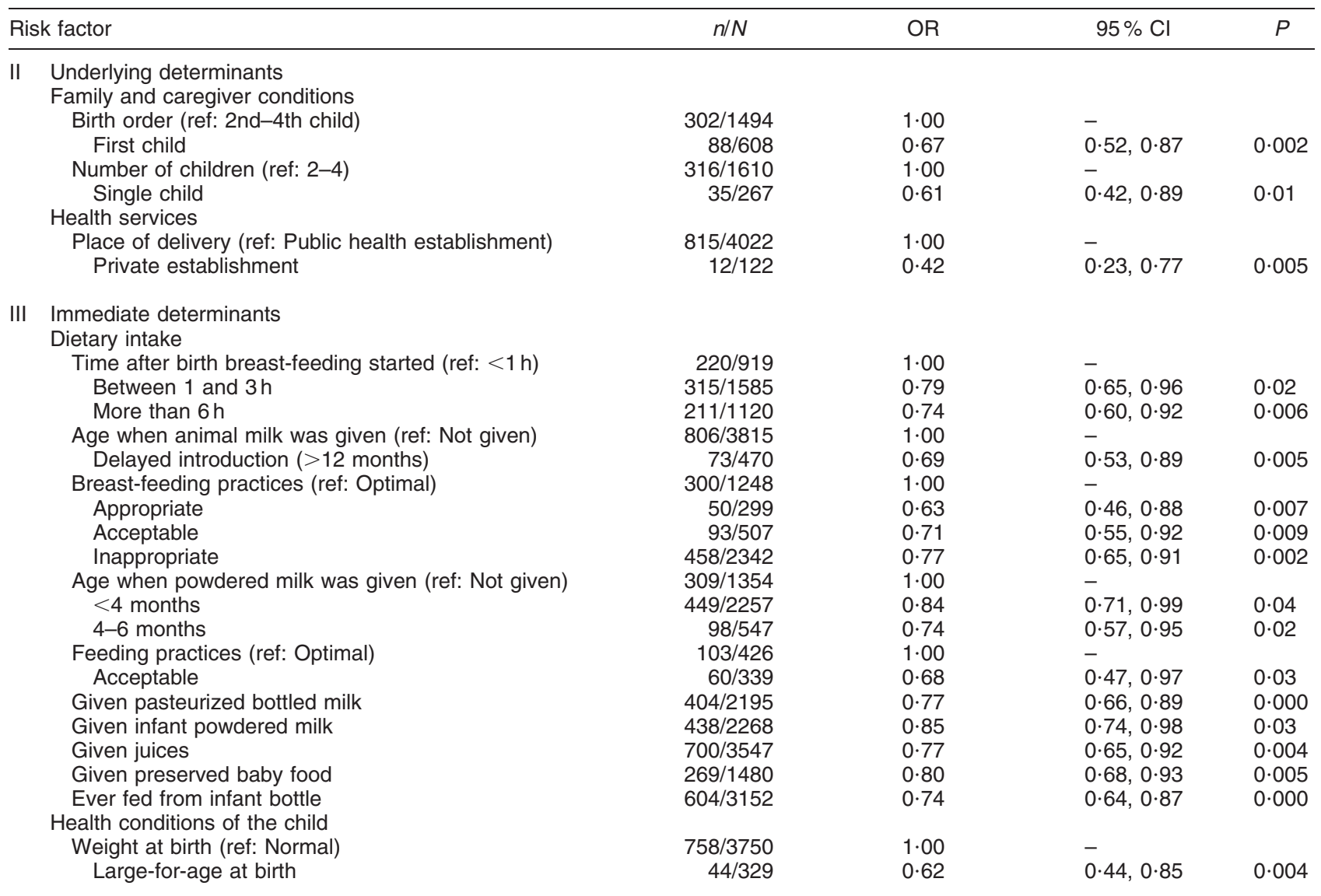

$n$, number of stunted children in the category; $N$, total number of children in the category.

\section{Discussion}

Libya is a country with an intermediate level of income, with a per capita gross domestic product of \$US 6418 in $1995^{(19)}$. A number of programmes were implemented to improve the nutritional status of the population in the second half of the last century. Large amounts of resources were spent on food subsidy programmes and also on food distribution activities for women and children $^{(15)}$. A nutritional surveillance system was introduced in maternal and child health centres. There have been marked improvements over the past few decades in the nutritional status of children ${ }^{(15,20)}$. However, much work remains to be done ${ }^{(15)}$. 
Table 5 Multivariate analysis of risk factors associated with stunting in under-fives in Libya: secondary analysis of data from the Libyan Maternal and Child Health Survey, 1995

\begin{tabular}{|c|c|c|c|c|}
\hline \multicolumn{2}{|c|}{ Risk factor } & \multirow[t]{2}{*}{ OR } & \multirow[t]{2}{*}{$95 \% \mathrm{Cl}$} & \multirow[t]{2}{*}{$P$} \\
\hline I & Basic determinants & & & \\
\hline & Resident of Al-Akhdar (ref: Benghazi) & $1 \cdot 67$ & $1 \cdot 08,2 \cdot 58$ & 0.02 \\
\hline & Age (ref: $4-<5$ years) & & & \\
\hline & $1-<2$ years & $2 \cdot 32$ & $1 \cdot 67,3 \cdot 22$ & 0.0001 \\
\hline & $2-<3$ years & $1 \cdot 64$ & $1 \cdot 22,2 \cdot 21$ & 0.001 \\
\hline & Boys & $1 \cdot 28$ & $1 \cdot 05,1 \cdot 55$ & $0 \cdot 02$ \\
\hline \multirow[t]{12}{*}{ II } & Underlying determinants & & & \\
\hline & Family and care giver conditions & & & \\
\hline & Father's educational status (ref: University) & & & \\
\hline & Illiterate & $2 \cdot 10$ & $1 \cdot 17,3 \cdot 77$ & 0.01 \\
\hline & Preparatory & $1 \cdot 71$ & $1 \cdot 11,2 \cdot 65$ & 0.02 \\
\hline & Family goes on no trips or visits & $1 \cdot 52$ & $1 \cdot 07,2 \cdot 16$ & 0.02 \\
\hline & Father rarely/never plays with child (ref: Almost every day) & $2 \cdot 24$ & $1 \cdot 20,4 \cdot 16$ & 0.01 \\
\hline & Father's age $>50$ years at birth (ref: $>30-50$ years) & 0.53 & $0.32,0.90$ & 0.02 \\
\hline & Household environment & & & \\
\hline & Water storage in tanks (ref: No water storage) & $0 \cdot 70$ & $0.54,0.90$ & 0.006 \\
\hline & Water treatment by filtering (ref: No treatment) & $8 \cdot 45$ & $2 \cdot 31,30 \cdot 95$ & 0.001 \\
\hline & Garbage is thrown in the street (ref: Plastic bags) & $13 \cdot 81$ & $2 \cdot 33,81 \cdot 72$ & $0 \cdot 004$ \\
\hline \multirow[t]{4}{*}{ III } & Immediate determinants & & & \\
\hline & Health conditions of the child & & & \\
\hline & Diarrhoea & $1 \cdot 58$ & $1 \cdot 09,2 \cdot 29$ & 0.02 \\
\hline & Low birth weight & $1 \cdot 68$ & $1 \cdot 17,2 \cdot 40$ & 0.005 \\
\hline
\end{tabular}

This is the first time that data have been exploited to formulate a hypothesis on possible factors determining the problem of undernutrition among under-fives in Libya. One of the important aspects of this survey is that it was performed during the peak of political and economic difficulties that faced the country in the 1990s following UN sanctions and the counteracting measures that were taken. The result was a many-fold rise in the price of most food items.

We did not find any evidence of significant collinearity in our model. However, certain inherent limitations may arise in the study such as the difficulty to examine temporal relationships, differences in seasonal distribution of risk factors, recall bias, absence of data on maternal nutrition and food practices of the family, absence of data on parasitic infections, absence of comprehensive data on mental health of the family including different psychosocial stimulation and/or interaction between family members, and the possibility that respondents would answer in more socially desirable ways. Standard national cross-sectional studies such as PAPCHILD, the Pan Arab Project for Family Health and Multiple Indicator Cluster Surveys do not evaluate measures taken by different authorities to combat undernutrition.

The complex interrelated factors associated with stunting that we found in the current study are represented according to the UNICEF conceptual framework (Fig. 1). The results of our study show the importance of the UNICEF model incorporating parental and socioeconomic characteristics in understanding the prevalence of stunting in Libya. However, such models should be interpreted only from an exploratory point of view ${ }^{(11)}$.
Models constitute a platform for better comprehension of potential dynamics and possible sites of intervention ${ }^{(21)}$. The paths indicated by the arrows in the UNICEF framework are meant to suggest distal $v$. proximal relationships, and do not necessarily mean that distal factors cannot have direct effects on stunting.

In the current study, being from the less privileged groups was a risk factor initially but disappeared in subsequent multivariate analysis. The effects of income are known to be mediated through other underlying determinants ${ }^{(4,12)}$. These factors determine the ability of the family to combine their knowledge, resources and patterns of behaviour, to promote, recover or maintain health status and to cope with a difficult environment ${ }^{(4,11,12)}$. Such factors include parental education, psychosocial stimulation and household environment ${ }^{(4,12,22-24)}$.

In spite of equity-driven health and education service expansion in Libya during the 1970s, stunting was related to living in rural areas as well as in certain geographical regions. Stunting is known to be more prevalent in rural areas $^{(22)}$. People living in urban areas are provided with better access to health services, education and other social support systems which are either not available or not easily accessible to residents in rural areas. The two regions with the highest risk for stunting were the two mountainous areas. A strong inverse association between child height and altitude has been noticed previously. Possible explanations could include access to food, dietary habits, living practices, environmental conditions such as cold climate, hygienic measures such as water supply, and parasitic infections ${ }^{(7,25)}$. These findings may also reflect the absence of vertical expansion that 


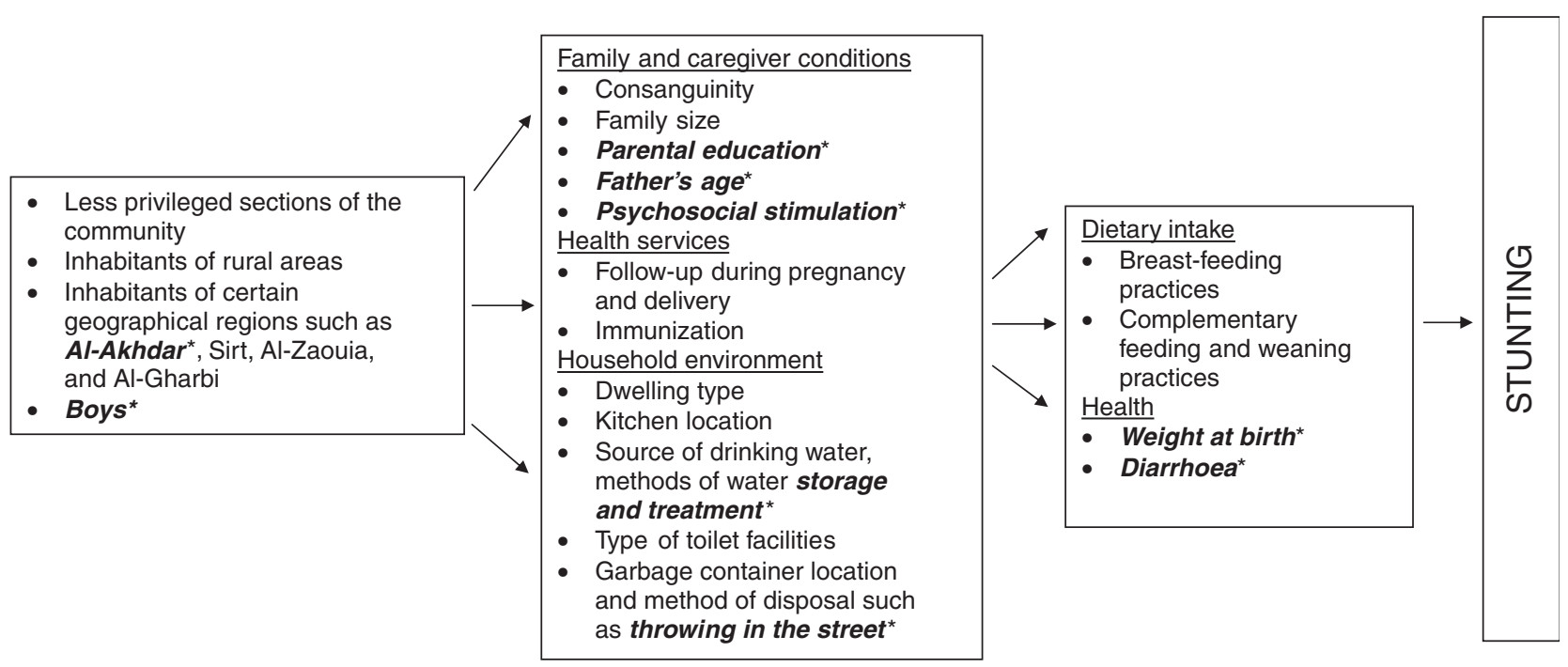

Fig. 1 Explanatory model and possible interactions of different risk factors associated with stunting among under-five children in Libya based on the UNICEF conceptual framework ${ }^{(8)}$ of the determinants of nutritional status (*bold italic font indicates those factors that persisted in the multivariate model)

should have followed the horizontal expansion which occurred in the country during the 1970s. Further studies are needed to verify the exact role of these factors in this population.

Gender is an important aspect of equity. Equal degree of undernutrition between under-five boys and girls by the year 2020 is accepted as a mean for evaluating gender equity in different societies ${ }^{(11,26)}$. There is no evidence of gender bias in stunting in Libya based on the current study.

On occasions, children may be born undernourished due to growth retardation in utero and their growth may improve exponentially over time ${ }^{(11,12,22,23)}$. On other occasions, the anthropometric status of children worsens considerably only when they are weaned and particularly if low-quality solid foods are introduced. In the current study, stunting was associated with age period of 1-3 years. Other factors increasing the risk of stunting in this age period include loss of passive immunity, exposure to unsanitary conditions increasing the risk of infections that suppress appetite and directly affect nutrient metabolism, and return of the mother to work $^{(11,23,27)}$.

In the current study, paternal education and age were significant factors associated with stunting in the final model. Higher education could reflect higher income and more paternal interest in child nutrition. More educated fathers are more likely to have educated wives. Educated mothers are known to be older at their first birth and are more knowledgeable about care practices. Educated families live in smaller households, in better houses, they are better able to use health-care facilities, and are more adept at keeping their environment clean ${ }^{(11,12,28)}$.
Parental consanguinity was a significant factor associated with stunting in bivariate analysis in the current study, but it disappeared in multivariate analysis indicating that it was a confounding variable. Studies have shown conflicting results on the impact of consanguineous marriages on child health ${ }^{(29)}$.

Indicators for health services utilization such as incomplete immunization, poor check-up during pregnancy and non-supervised deliveries were all risk factors for stunting. These factors are known to influence stunting both directly and indirectly. Health knowledge and access to health care could also explain regional differences in undernutrition ${ }^{(11,23)}$, as in Libya.

Environmental factors refer to the availability of safe water, sanitation and environmental safety, including shelter. Environmental factors such as poor housing and exposure to untreated water are known to be associated with stunting ${ }^{(30,31)}$. In fact, most of the positive effect of income on child height could be mediated by the quality of family housing ${ }^{(7,12)}$. In the current study, household quality was an important risk factor in the multivariate model. In some regions of Libya and in spite of major drinking water projects, many people have to use variable methods to obtain a continuous water supply or more palatable water. Examples include boiling of water from superficial wells and the use of desalinated or filtered water from near-by factories. Such water may be either contaminated, thereby predisposing children to repeated bouts of infection, or lacking in some micronutrients, which might compromise growth. Having piped water in the home also reflects higher income levels and/or that the environmental sanitation in these homes is better. 
When water is not readily available, food hygiene is frequently poor, which increases the risk of pathogen contamination and exposure to illnesses. However, the fact that storing water in tanks protects against infections in comparison to publicly supplied piped water calls for better quality control of this system.

Diarrhoea is a known risk factor for stunting ${ }^{(11,23,30)}$. The current survey was conducted during the summer. The prevalence of diarrhoea from our data was found to be $17 \cdot 3 \%$ (779/4498). Diarrhoea could be related to food preparation and feeding practices and to increased exposure to pathogens as children become increasingly mobile throughout the first three years of life. As children get older, they may become more immune to infections due to a gradual increase in the colonization of various bacteria and viruses in the gut. Targeting health education messages to mothers with children younger than 3 years old may be an important option to consider.

Breast milk contains the mix of nutrients that is best suited to the infant's metabolism. An initial period of exclusive breast-feeding is essential to lower the risk of stunting, after which supplementary foods should be introduced appropriately into the child's diet ${ }^{(24)}$. The use of bottle feeding predisposes to infections and may be associated with diluted non-nutritive formula preparation ${ }^{(24)}$. Early introduction of complementary foods is a known predictor of undernutrition ${ }^{(23)}$, but there is a debate as to the most suitable age that supplements should be first given ${ }^{(32)}$. In the current study, breast-feeding was considered optimal if it started early, if it was continued for $>12$ months and if weaning started at 6-8 months. It was considered appropriate if weaning started earlier (between 4 and 6 months). In the current study, optimal breast-feeding was not as protective as appropriate breast-feeding. In addition, there was a protective effect of bottle feeding and early introduction of breast milk substitutes such as powder milk or pasteurized bottled milk. Previous studies reported a similar observation where, for example, longer breast-feeding was associated with both higher stunting and severe stunting risk $^{(24)}$. This should be viewed as failure of optimal complementary feeding and the inability of the household to provide supplemental foods, and should not be an argument for advertising of these substitutes ${ }^{(11)}$. In other cases, when a child is severely stunted, mothers may respond by a decision to continue breast-feeding ${ }^{(24,33)}$. Moreover, none of the dietary intake factors in the current study persisted in the multivariate model.

Low birth weight is a known correlate of stunting ${ }^{(12,28)}$. In the current study, it had a potent effect on stunting that persisted in the single multivariate analysis. The known effect of low birth weight on child health makes it the most relevant single factor for children's survival ${ }^{(34)}$.

To fight undernutrition sustainably, changes in many of the underlying factors are necessary ${ }^{(11)}$. In spite of the existence of food security programmes in Libya, the broader concept of nutritional security should be imple- mented. This is achieved for a household when secure access to food is coupled with a sanitary environment, adequate health services and knowledgeable care. As in other studies, the risk factors of stunting that we found were diverse, complex, difficult to manage, and their effects started even before birth ${ }^{(35)}$. The current study provides relevant information for determining courses of action to be taken at the meso and micro level to improve the nutrition and health of children in Libya. Policy frameworks must be established that incorporate short-, medium- and long-term strategies to solve nutritional problems in Libya. Corresponding intervention strategies should be comprehensive, culturally sensitive and addressed at various levels. Programmes should specifically target higher-risk groups such as young children (1-3 years), residents of Al-Akhdar, boys, less educated fathers, poor family social life, low-quality household environment, diarrhoea and low birth weight. Particular attention should be given to the particularly brief window of intervention from the mother's pregnancy through the child's first two years of life. Further research, particularly on regional differences, is required to design relevant and effective intervention programmes.

\section{Acknowledgements}

There are no conflicts of Interest and no sources of funding.

Authors' contributions: A.E.T. was responsible for data analysis and interpretation, performed statistical analysis and drafted the paper. O.G. and S.M.M. supervised data analyses and contributed to interpretation of data. P.G. and S.H. contributed to drafting the paper. A.A.M. and I.B. were responsible for study design and coordinated the supply of the data. All contributors were involved in critical revision of the paper.

\section{References}

1. Goldstein H \& Tanner JM (1980) Ecological considerations in the creation and the use of child growth standards. Lancet 1, 582-585.

2. de Onis M, Monteiro C, Akre J \& Glugston G (1993) The worldwide magnitude of protein-energy malnutrition: an overview from the WHO Global Database on Child Growth. Bull World Health Organ 71, 703-712.

3. United Nations Administrative Committee on Coordination/Sub-Committee on Nutrition (2000) Fourth Report on the World Nutrition Situation: Nutrition Through the Life Cycle. Geneva: ACC/SCN.

4. Reyes H, Perez-Cuevas R, Sandoval A, Castillo R, Santos JI, Doubova SV \& Gutiérrez G (2004) The family as a determinant of stunting in children living in conditions of extreme poverty: a case-control study. BMC Public Health 4, 57.

5. Pelletier DL (1994) The potentiating effects of malnutrition on child mortality: epidemiologic evidence and policy implications. Nutr Rev 52, 409-415.

6. Khuwaja S, Selwyn BJ \& Shah SM (2005) Prevalence and correlates of stunting among primary school children 
in rural areas of southern Pakistan. J Trop Pediatr 51, $72-77$.

7. Behrman JR \& Skoufias E (2004) Correlates and determinants of child anthropometrics in Latin America: background and overview of the symposium. Econ Hum Biol 2, 335-351.

8. UNICEF (1990) Strategy for Improved Nutrition of Children and Women in Developing Countries. New York: Oxford University Press.

9. World Health Organization (1990) Appropriate Uses of Anthropometric Indices in Children. ACC/SCN Stateof-the-Art Series, Nutrition Policy Discussion Paper no. 7. Geneva: WHO.

10. Kirkwood B \& Sterne J (2003) Essential Medical Statistics, 2nd ed. Oxford: Blackwell Science.

11. Caputo A, Foraita R, Klasen S \& Pigeot I (2003) Undernutrition in Benin - an analysis based on graphical models. Soc Sci Med 56, 1677-1691.

12. Aerts D, Drachler Mde L \& Giugliani ER (2004) Determinants of growth retardation in Southern Brazil. Cad Saude Publica 20, 1182-1190.

13. The General People's Committee for Health and Social Affaires (1996) The Pan Arab Project for Child Development, The Libyan Maternal and Child Health Survey. Principal Report. Sert, Libya: The General People's Committee for Health and Social Affairs.

14. World Health Organization (2005) Libyan Arab Jamahiriya. WHO Global Database on Child Growth and Malnutrition. http://www.who.int/nutgrowthdb/database/countries/lby/ en/ (accessed April 2008).

15. El Taguri A, Rolland-Cachera M-F, Mahmud SM, Elmrzougi N, Abdel Monem A, Betilmal I \& Lenoir G (2007) Nutritional status of under-five children in Libya: a national population-based survey. Libyan J Med AOP: 071006.

16. WHO Multicentre Growth Reference Study (2006) Enrolment and baseline characteristics in the WHO Multicentre Growth Reference Study. Acta Paediatr Suppl 450, 7-15.

17. League of Arab States, Pan Arab Project for Child Development (2006) Arab Maternal and Child Health Survey. http://www.papfam.org/arab_league/about_PAPFAM.htm (accessed 2006).

18. El-Tajouri RF (1979) Cross sectional study of growth in urban pre-school children in Libya. PhD Thesis, University of Zurich, Switzerland.

19. International Monetary Fund (2008) Data and Statistics, World Economic Outlook. http://www.imf.org/external/ datamapper/index.php (accessed April 2008).

20. International Bank for Reconstruction and Development (1960) The Economic Development of Libya. Report of a mission organized by the International Bank for Reconstruction and Development. Baltimore, MD: The Johns Hopkins Press.
21. Bar-Yam Y (2006) Improving the effectiveness of health care and public health: a multiscale complex systems analysis. Am J Public Health 96, 459-466.

22. Steyn NP, Labadarios D, Maunder E, Nel J \& Lombard C (2005) Secondary anthropometric data analysis of the National Food Consumption Survey in South Africa: the double burden. Nutrition 21, 4-13.

23. Bloss E, Wainaina F \& Bailey RC (2004) Prevalence and predictors of underweight, stunting, and wasting among children aged 5 and under in western Kenya. J Trop Pediatr 50, 260-270.

24. Brennan L, McDonald J \& Shlomowitz R (2004) Infant feeding practices and chronic child malnutrition in the Indian states of Karnataka and Uttar Pradesh. Econ Hum Biol 2, 139-158.

25. Dang S, Yan H \& Yamamoto S (2008) High altitude and early childhood growth retardation: new evidence from Tibet. Eur J Clin Nutr 62, 342-348.

26. Wamani H, Astrom AN, Peterson S, Tumwine JK \& Tylleskar T (2007) Boys are more stunted than girls in sub-Saharan Africa: a meta-analysis of 16 demographic and health surveys. BMC Pediatr 7, 17.

27. Branca F \& Ferrari M (2002) Impact of micronutrient deficiencies on growth: the stunting syndrome. Ann Nutr Metab 46, Suppl. 1, 8-17.

28. Marins VM \& Almeida RM (2002) Undernutrition prevalence and social determinants in children aged 0-59 months, Niteroi, Brazil. Ann Hum Biol 29, 609-618.

29. Bittles AH (2003) Consanguineous marriage and childhood health. Dev Med Child Neurol 45, 571-576.

30. Fernandez ID, Himes JH \& de Onis M (2002) Prevalence of nutritional wasting in populations: building explanatory models using secondary data. Bull World Health Organ 80, 282-291.

31. El-Sayed N, Mohamed AG, Nofal L, Mahfouz A \& Zeid HA (2001) Malnutrition among pre-school children in Alexandria, Egypt. J Health Popul Nutr 19, 275-280.

32. Reilly JJ \& Wells JC (2005) Duration of exclusive breastfeeding: introduction of complementary feeding may be necessary before 6 months of age. Br J Nutr 94, 869-872.

33. Caulfield LE, Bentley ME \& Ahmed S (1966) Is prolonged breastfeeding associated with malnutrition? Evidence from nineteen demographic and health surveys. Int J Epidemiol 25, 693-703.

34. WHO Working Group (1986) Use and interpretation of anthropometric indicators of nutritional status. Bull World Health Organ 64, 929-941.

35. Rappaport R (1987) Endocrine control of growth. In Linear Growth Retardation in Less Developed Countries. Nestlé Nutrition Workshop Series, vol. 14, pp. 109-126 [JC Waterlow, editor]. New York: Raven Press. 